\title{
Optimal Regulators Conception for Wind Turbine PMSG Generator Using Hooke Jeeves Method
}

\author{
Lakhdar Mazouz $^{1 *}$, Sid Ahmed Zidi², Ahmed Hafaifa', Samir Hadjeri², Tahar Benaissa \\ ${ }^{1}$ Department of Electrical Engineering, Faculty of Technology, University of Djelfa, B P 3117, Djelfa, Algeria \\ 2 Department of Electrotechnique, Faculty Electrical Engineering, University of Sidi-Bel-Abbès BP 8922000 , \\ Sidi-Bel-Abbès, Algeria \\ * Corresponding author, e-mail: mazouzlak@gmail.com
}

Received: 04 December 2018, Accepted: 20 February 2019, Published online: 15 April 2019

\begin{abstract}
This paper explores the optimization of wind turbine control system parameters. The wind turbine based on 5 MW PMSG Permanent magnet synchronous generator with two back-to-back converters which are connected to AC offshore network. For good functioning of the control system based on PI regulators, it is necessary to find a perfect way for calculating the gains of these regulators. In this paper, Hooke Jeeves method is presented as one of optimization solutions that can compute parameters of PI regulators. For this purpose, a model of offshore wind turbine is installed in PSCAD/EMTD in order to perform simulation study in which optimal $\mathrm{PI}$ regulators design can be found.
\end{abstract}

Keywords

PMSG generator, Hooke Jeeves method, optimization, PI regulator, wind turbine, wind energy, outer control, inner control

\section{Introduction}

Today, wind energy is one of the most dynamic sources of electricity and one of the most dynamic markets in the world. The appearance of the wind as a major source of energy in the world can be classified as one of the main developments of this century. These most important changes can be related to several benefits associated with wind energy. The first benefit is that wind energy is clean energy to produce electricity. The second advantage is that all machines needed to produce wind power are manufactured and available around the world; this leads to a cost-competitive electricity source. Another advantage is that wind turbines require only half-yearly maintenance with low maintenance; Compared to other systems where the maintenance costs are very high.

For coming years, the EU's renewable energy forecasts aim to produce $20 \%$ of global energy from renewable energy sources by 2020. In order to achieve this goal, EWEA has set a target of develop $230 \mathrm{GW}$ of wind energy in which $40 \mathrm{GW}$ will come from offshore wind farms [1]. By 2030, the total installed wind power will be $400 \mathrm{GW}$, of which $150 \mathrm{GW}$ will be from offshore wind installations. However, thanks to a better capacity factor, offshore wind energy will contribute about half total wind energy production [2].
For offshore wind energy production and for the conception of the turbines which can satisfy this production, one of good solutions is the use the PMSG generator, thanks to its advantages as simplicity and robustness of functioning. This machine has an important role in the offshore wind turbines conception because the magnets included in the generator provide a constant magnetic field avoiding the need for independent electrical excitation [3], but the use of PI element in the control system design for this machine is limited by a big challenge which is the selection of appropriate PI parameters. Authors in [4-7] use lot of methods to find PI gains in order to improve the work of the control system. In [5] FBO has the advantage of high accuracy but it has the disadvantage of time consuming. In [6] PSO can find quickly the new gains but it has the drawback of low accuracy. In [4] hybrid PSO-FBO is used to eliminate the previous problems. The simplex method in [7] is also used to optimize the initial PI gains by using the ISE criterion (the integral of the error square) but the problem with this method in PSCAD software is the high number of multiple runs which take long time. Adding to these related works, this paper presents Hooke Jeeves method as a method of optimization to compute 
new PI gains starting at initial ones taken from conventional method.

\section{Modeling and control of the wind turbine}

The wind turbine is a machine that converts the kinetic energy of the wind into mechanical energy, which in turn is converted into electrical energy [8]. A simplified diagram of the wind turbine with its control is presented in Fig. 1. The power produced by the wind turbine is transferred through back-to-back power converters; therefore, the dynamic operation of the electric generator is effectively isolated from the electrical network thus allowing operation at variable speed of the wind turbine.

For the control of this wind turbine, the generator-side converter regulator controls the DC voltage of the back-toback link and the reactive power, while the $\mathrm{AC}$-side converter regulator of the wind turbine maintains the AC offshore voltage and the frequency. The speed of the wind turbine will be assumed constant in this work.

The equations in $d-q$ axes used to model the synchronous permanent magnet generator are [9-11]:

$$
\begin{aligned}
& V_{d s}=R_{s} I_{d s}+\frac{d \varphi_{d s}}{d t}-\omega_{r} \varphi_{q s} \\
& V_{q s}=R_{s} I_{q s}+\frac{d \varphi_{q s}}{d t}+\omega_{r} \varphi_{d s}
\end{aligned}
$$

$$
\begin{aligned}
& \varphi_{d s}=L_{d s} I_{d s}+P_{s i} \\
& \varphi_{q s}=L_{q s} I_{q s} .
\end{aligned}
$$

With:

$V_{q s}:$ The $q$ axis component of the stator voltage vector;

$V_{d s}:$ The $d$ axis component of the stator voltage vector;

$I_{d s}$ : The $d$ axis component of the stator current vector;

$I_{q s}$ : The $q$ axis component of the stator current vector;

$R_{s}$ : The simple resistance of the stator winding;

$L_{d s}:$ Stator inductance in $d$-axis;

$L_{q s}:$ Stator inductance in $q$-axis;

$\varphi_{d s}$ : The $d$ axis component of the stator flux vector;

$\varphi_{q s}$ : The $q$ axis component of the stator flux vector;

$P_{s i}$ : The permanent flux of the magnetic.

The equations of the active and reactive powers generated by the generator:

$P_{s}=-3\left(V_{d s} I_{d s}+V_{q s} I_{q s}\right)$

$Q_{s}=-3\left(V_{d s} I_{q s}-V_{q s} I_{d s}\right)$.

The equation of the DC power of back-to-back link is:

$$
P_{d c 1}=U_{d c} I_{d c 1} \text {. }
$$

Neglecting the losses in the converter, so $P_{d c 1}=P_{s}$.

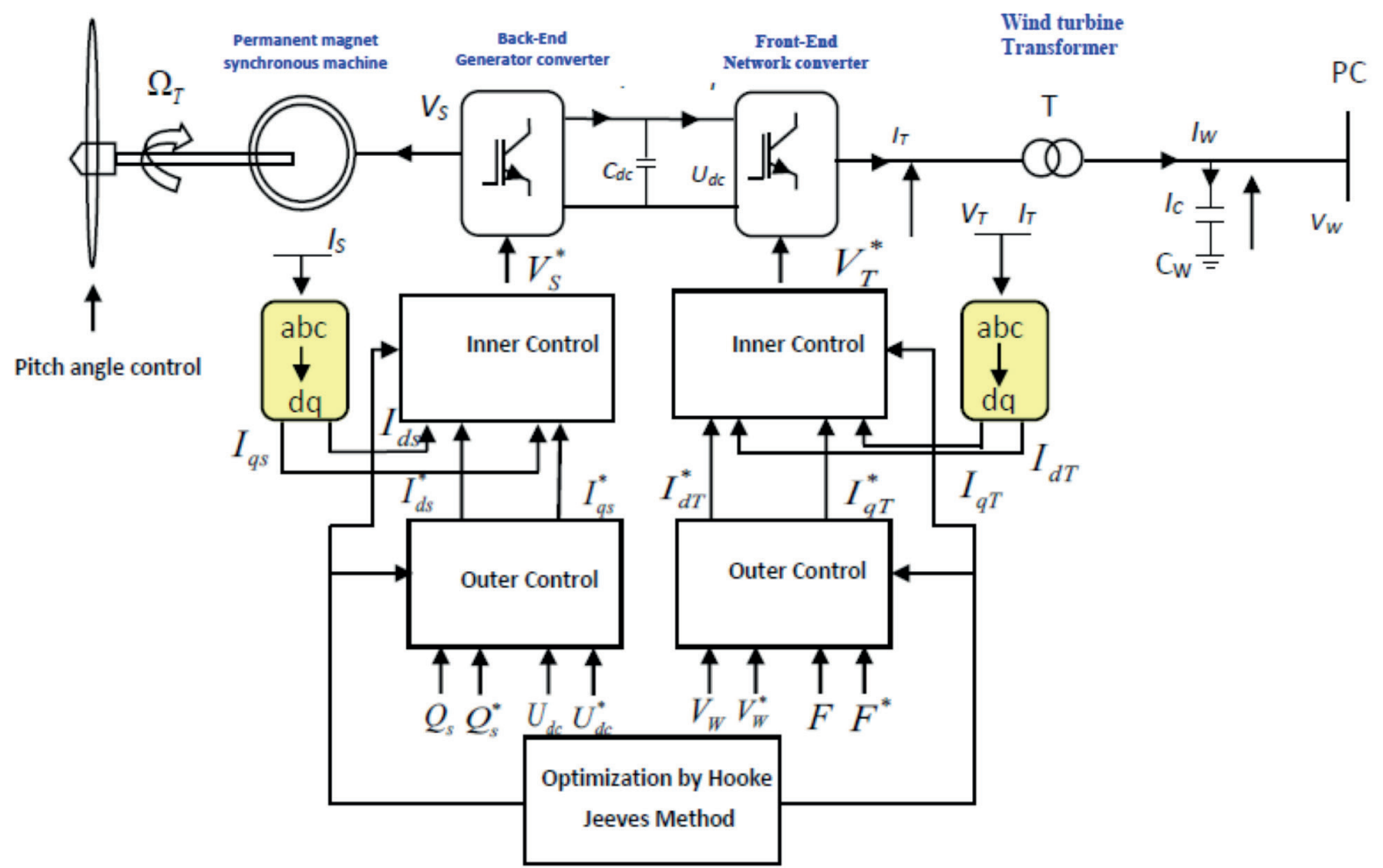

Fig. 1 Simplified diagram of the wind turbine and its control 
The dynamics of the voltage $U_{d c}$ is defined by the equation of capacitance $C_{d c}$ and it can be expressed as follows:

$I_{d c 1}-I_{d c 2}=C_{d c} \frac{d U_{d c}}{d t}$

The equations of the power at the converter side of the offshore grid are:

$P_{d c 2}=U_{d c} I_{d c 2}$

$P_{T}=3\left(V_{d T} I_{d T}+V_{q T} I_{q T}\right)$.

The dynamics of the offshore network integration can be written in synchronous coordinates $d-q$ as follows [12]:

$\frac{d}{d t} I_{d T}=-\frac{R_{T}}{L_{T}} I_{d T}+\omega_{T} I_{q T}+\frac{1}{L_{T}} V_{d T}-\frac{1}{L_{T}} V_{d w}$

$\frac{d}{d t} I_{q T}=-\frac{R_{T}}{L_{T}} I_{q T}-\omega_{T} I_{d T}+\frac{1}{L_{T}} V_{q T}$.

From Eq. (1) and Eq. (2), the active and reactive currents control at the rectifier side is [13]:

$u_{d s}=R_{s} I_{d s}+\frac{d \varphi_{d s}}{d t}$

$u_{q s}=R_{s} I_{q s}+\frac{d \varphi_{q s}}{d t}$

From Eq. (5), Eq. (7), Eq. (8) and assuming that the field current reference is set to zero, the control of the DC voltage is expressed as follows:

$U_{U d c}=\frac{d U_{d c}^{2}}{d t}=-\frac{1}{C_{d c}}\left(6 V_{q s} I_{q s}+2 U_{d c} I_{d c 2}\right)$.

From Eq. (6), the control of the reactive power is written as follows:

$I_{q s}^{*}=\frac{-1}{3 V_{d s}} Q_{s}^{*}$.

From Eq. (11) and Eq. (12), the control of active and reactive currents on the offshore inverter side is:

$$
\begin{aligned}
& \frac{d}{d t} I_{d T}+\frac{R_{T}}{L_{T}} I_{d T}=\omega_{T} I_{q T}+\frac{1}{L_{T}} V_{d T}-\frac{1}{L_{T}} V_{d w} \\
& \frac{d}{d t} I_{q T}+\frac{R_{T}}{L_{T}} I_{q T}=-\omega_{T} I_{d T}+\frac{1}{L_{T}} V_{q T} \\
& u_{d T}=\frac{d}{d t} I_{d T}+\frac{R_{T}}{L_{T}} I_{d T} \\
& u_{q T}=\frac{d}{d t} I_{q T}+\frac{R_{T}}{L_{T}} I_{q T} .
\end{aligned}
$$

\section{Hooke Jeeves Optimization Method}

The Hooke and Jeeves method was originally published in 1961. The Hooke-Jeeves method is a direct method to minimize the objective function, which requires being continuous. The Hooke-Jeeves method calculates a new point using the values of the objective function at appropriate points around the initial point. The algorithm consists of exploratory move and pattern move [14-16]:

The exploratory move takes place along all Cartesian steps in the way of improving the value of the objective function, and then determining a new base point and a direction for the falling value of the objective function [17]. Pattern step advances in the direction of the connection of two adjacent base points to decrease the value of the objective function more rapidly.

\subsection{Algorithm}

1. Choose an initial point $x(0)$, variable increments $\Delta_{i}(i=1,2 \ldots \ldots . . N)$, reduction factor $\alpha>1$ and termination parameter $€$.

2. Do exploratory move as follow:

- Choose $x=x(0) i=1$ and variable increment $\Delta_{i}$.

- Compute $f=f(x), f^{+}=f\left(x_{i}+\Delta_{i}\right)$ and $f^{-}=f\left(x_{i}-\Delta_{i}\right)$.

- Find $f_{\min }=\min \left(f, f^{+}, f^{-}\right)$. Set $x$ corresponds to $f_{\min }$.

3. If $x \neq x_{c}$, success; go to 5 , If No

4. Check for the termination, $\|\Delta\|<\varepsilon, \Delta_{i}=\Delta_{i} / \alpha$ for $(i=1,2 \ldots \ldots . . N)$ and Go to 2 .

5. Do pattern move

Set $k=k+1$ and put $x_{p}(k+1)=x(k)+x(k)-x(k+1)$.

6. Perform exploratory move using $x_{p}$ as base point.

7. Is $f(x(k+1))<f(x(k))$ ? If yes put $x(k+1)=x(k)$ and go to 5 .

If No go to 4.

\subsection{Application of Hooke Jeeves method in the control system}

In order to improve the performance of the used PI regulators during normal operation and also against any disturbances that may occur, the parameters of these regulators will be improved using Hooke Jeeves algorithm. For this purpose, the control system performance is evaluated by the ISE criterion (the integral of the error square) [18]. The ISE index is expressed as follows:

$J_{I S E}=\int_{0}^{T} e(t)^{2} d t$. 
The objective of using this performance criterion is to correct control systems with long-lasting transient conditions and much less account for the overshoot of 1 [19]. According to this criterion, the design of the objective function is as follows:

$$
Q_{f}(X)=\sum_{i=1}^{6} \int_{0}^{T} e(t)^{2} d t
$$

Where: $e(t)$ is the error between the desired value and the existent one, $i$ presents the index of the regulator. And: $\quad X=K_{P 1}, K_{P 2} K_{P 3}, K_{P 4}, K_{P 5}, K_{P 6}, T_{i 1}, T_{i 2}, T_{i 3}, T_{i 4}, T_{i 5}$. The diagram corresponding to this objective function is shown in Fig. 2.

\section{Results}

In order to validate the optimization strategy described previously, simulation studies are carried out using PSCAD software. The control is applied in an offshore wind turbine based on 5MW permanent magnet synchronous generator with two back-to-back converters which are connected to the AC offshore network. The electrical parameters of the studied system are cited in the Table 1 in which some of them are taken from [20].

In order to prove the effectiveness of the presented method for finding new PI gains, the following simulations are performed.

\subsection{Step changes in reactive current reference at generator rectifier side}

A step change is applied in the reactive current reference $I_{q s}^{*}$ of the inner control loop at the rectifier side of the DC link. To do this, it is necessary to cross out the outer control loop in order to put the current reference at its

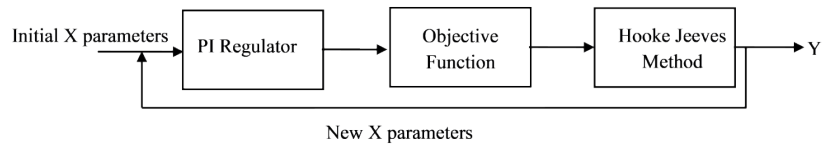

Fig. 2 Diagram of PI parameters optimization

Table 1 Electrical parameters of the model

\begin{tabular}{lcc}
\hline Parameters & Value & Unit \\
\hline Nominal power & 5 & MVA \\
Line voltage & 2 & $\mathrm{kV}$ \\
Rated frequency & 20 & $\mathrm{~Hz}$ \\
Number of poles & 80 & Pairs \\
DC voltage & 6.4 & $\mathrm{kV}$ \\
DC capacitor & 1000 & $\mathrm{uF}$ \\
Transformer & $5 \mathrm{MVA} / 50 \mathrm{~Hz}, 2 / 33(\mathrm{kV})$ & \\
\hline
\end{tabular}

reference value. The step is done at the moment $t=8 \mathrm{~s}$ for duration of $500 \mathrm{~ms}$ and after executing the simulation, the new parameters are cited in Table 2 .

The results are shown in Fig. 3, Fig. 4, Fig. 5 and Fig. 6. In all figures, the power and currents are with negative insignia because the machine works as generator. It is clearly seen from Fig. 3 that during the step change, the active power $P_{s}$ increases to some extent because this step force the generator to produce more reactive power

Table 2 PI parameters

\begin{tabular}{lccc}
\hline PI Parameters & $K p$ & $K i$ & Objective function \\
\hline Before optimization & 0.6 & 0.0016 & 1.15682 \\
After optimization & 0.431892 & 0.628981 & 0.529721 \\
\hline
\end{tabular}
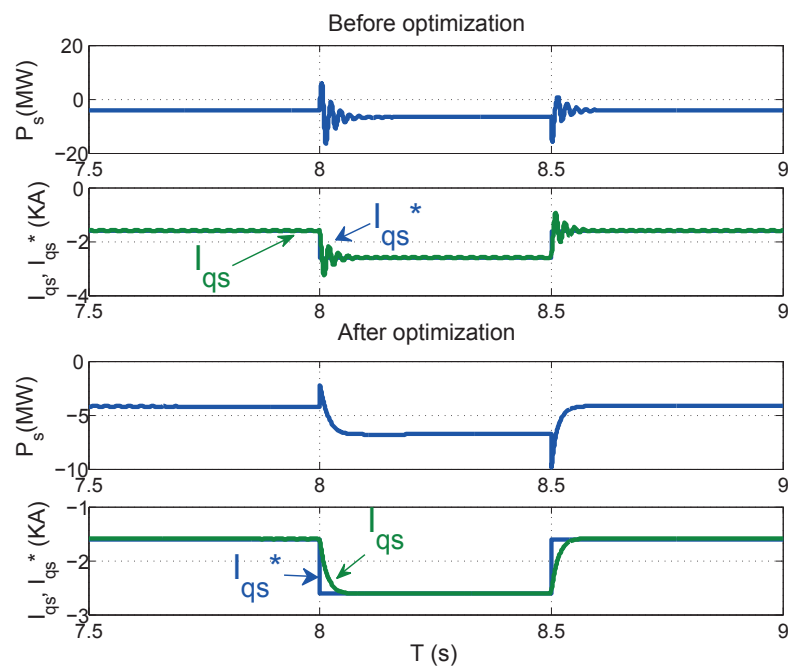

Fig. 3 Active power and reactive current during step applied in $I_{q s}^{*}$
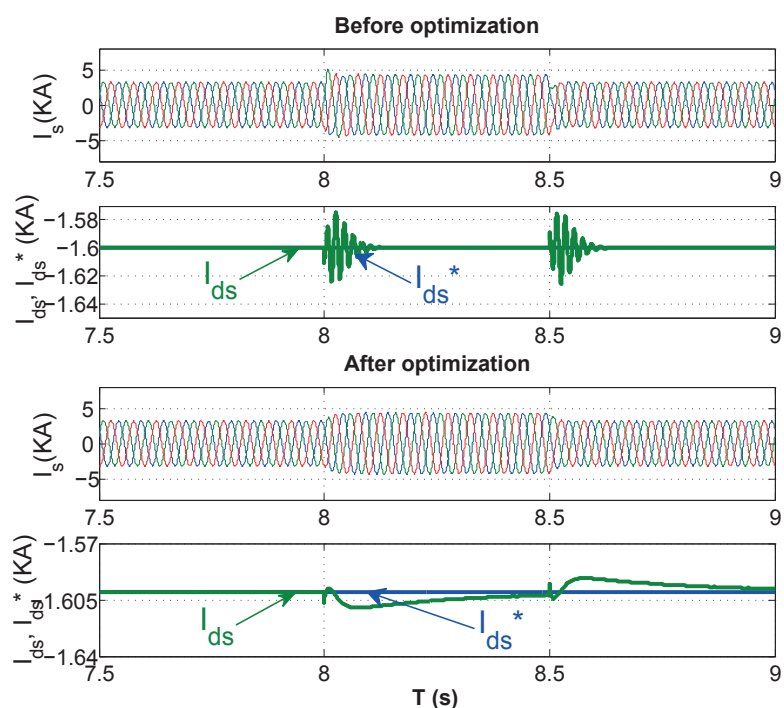

Fig. 4 AC current and active current during the step applied in $I_{q s}^{*}$ 

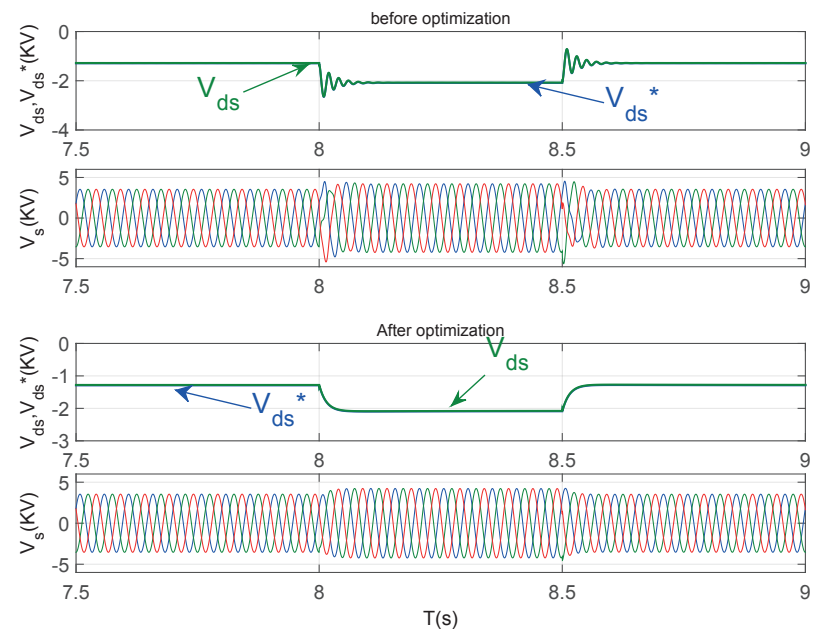

Fig. $5 \mathrm{AC}$ voltage and active voltage during the step applied in $I_{q s}^{*}$
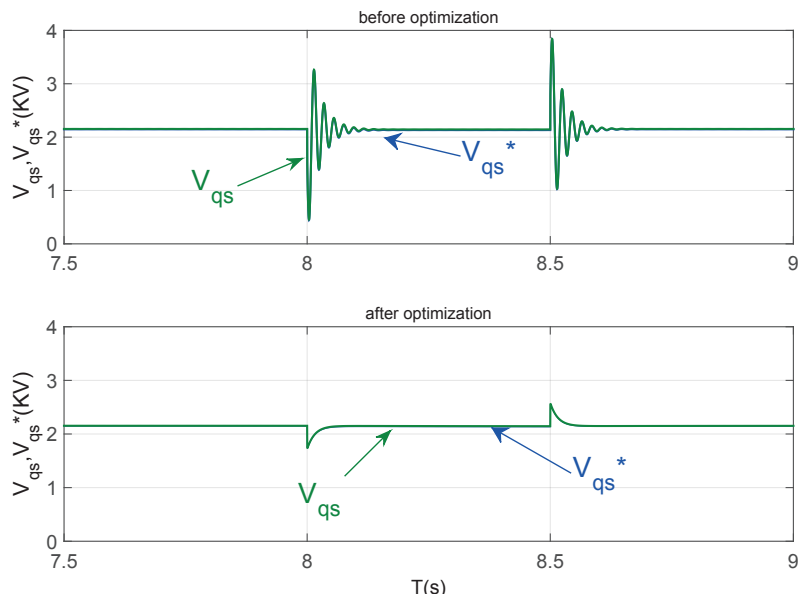

Fig. 6 Reactive voltage during the step change applied in $I_{q s}^{*}$

consumed by the capacitor installed as filter. This figure shows also that the influence of the Hooke Jeeves approach on the control system is clear in which the overshoots appears in the power before optimization are very important and also the time of response of the reactive current is very long compared to the results after optimization where the overshoots are eliminated and the response time becomes very short.

Fig. 4 presents the behavior of the currents during the step change. The AC current $I_{s}$ increases because of the reactive current augmentation and the active current $I_{d s}$ keeps its rated value whereas there are some oscillations before optimization. From this figure, the comparison shows that the effect of the optimization method to improve the behavior of the control is clear in which the oscillations caused by the converter is eliminated with the new PI parameters.
Fig. 5 presents the active voltage $V_{d s}$ and the AC voltage $V_{s}$ in which the behavior of the control system is improved after optimization compared to that with initial parameters. In Fig. 6, the reactive voltage is shown with large oscillations and also with huge response time. These phenomena are disappeared with the use of the optimization technique.

\subsection{Step changes in active current reference at turbine rectifier side}

A step change is applied in the active current reference $I_{d s}^{*}$ of the inner control loop. As the previous case, it is necessary to cross out the outer control loop and the active current reference is fixed at its reference value. The step is performed at the instant $t=6 \mathrm{~s}$ for duration of $600 \mathrm{~ms}$ and after executing the simulation, the new parameters are similar to the previous case (Table 1) because all PI regulators used in the inner control loop have the same parameters. Fig. 7 presents the active power with large oscillations and huge response time because of the use of initial PI gains but with the new ones these oscillations are eradicated and the response time is reduced. Also this figure shows clearly the reference active current $I_{d s}$ is well followed by its real current during the step change and the performance of the control system is well improved after Hook jeeves method use.

In Fig. 8 the reactive current $I_{q s}$ and the $\mathrm{AC}$ current $I_{s}$ are presented. The decrease of the active current $I_{d s}$ reduces the AC current $I_{s}$ generated by the generator without overshoots after optimization whereas before optimization the reactive current keeps its rated value with large oscillations. These oscillations are eradicated with the new computed PI gains.
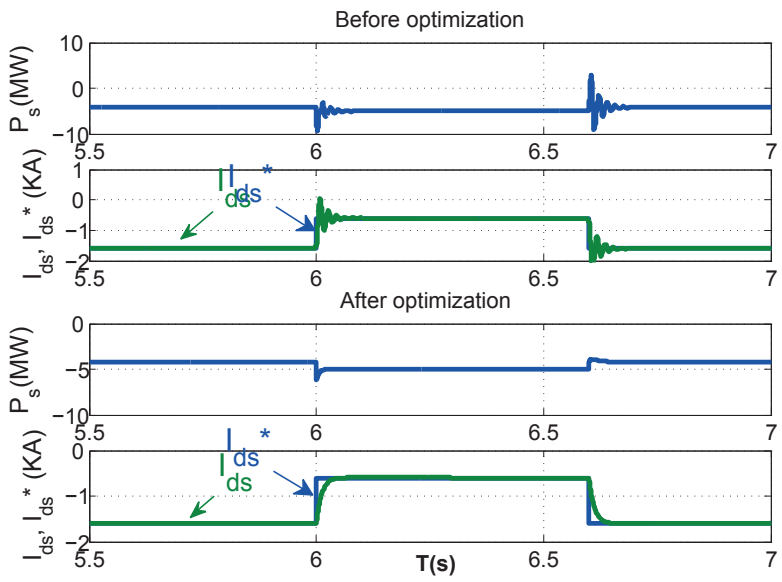

Fig. 7 Active power and active current during step applied in $I_{d s}^{*}$ 

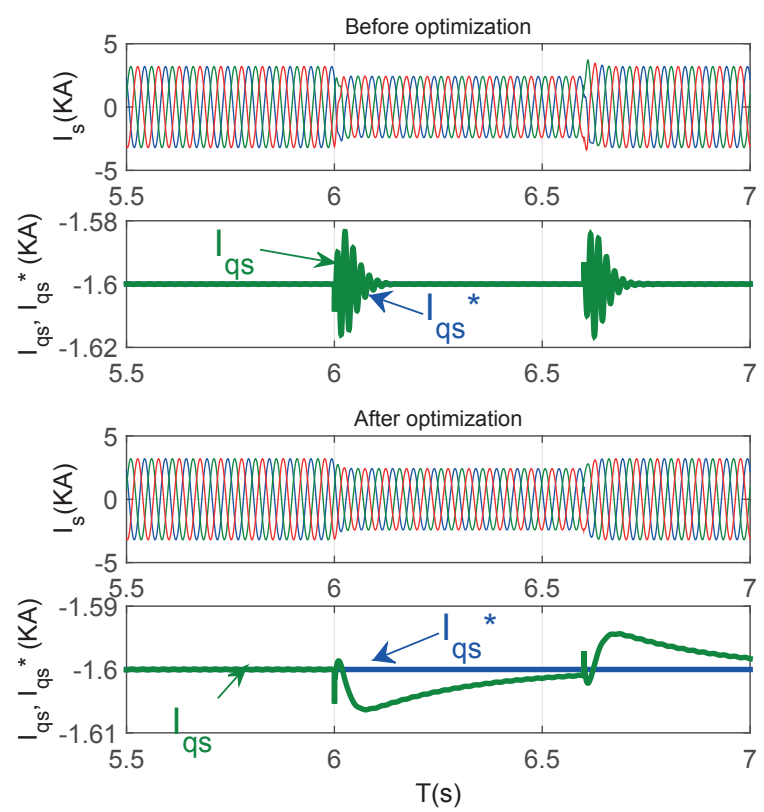

Fig. 8 AC current and reactive current during the step applied in $I_{d s}^{*}$
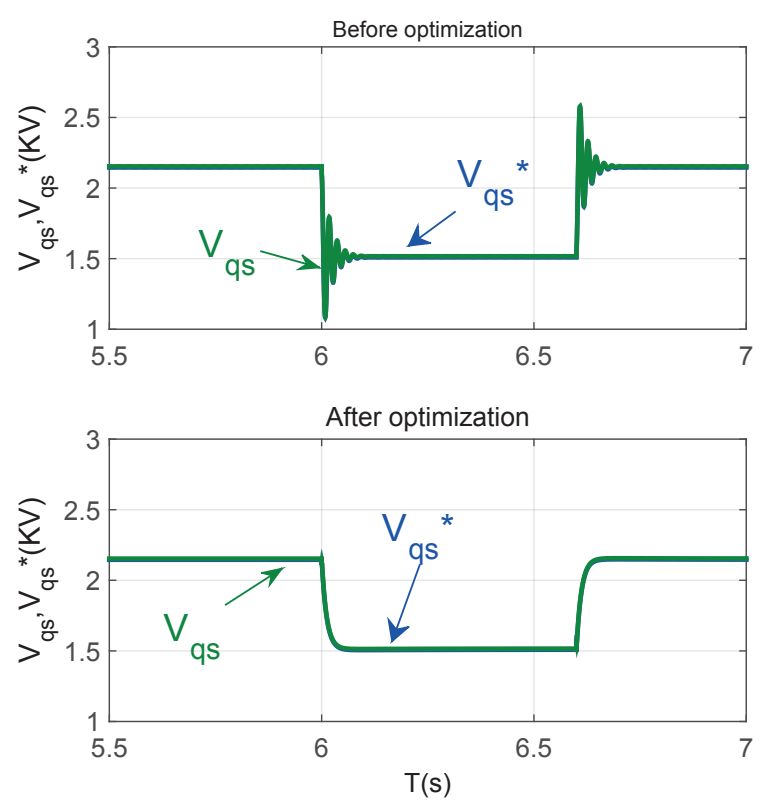

Fig. 10 Reactive voltage during the step change applied in $I_{d s}^{*}$

The active voltage $V_{d s}$ and the AC voltage $V_{s}$ are demonstrated in Fig. 9 where the performance of the control system is improved after optimization and this makes the whole system more robust and strong. In Fig. 10, the reactive voltage $V_{q s}$ is shown in two cases where the effect of the use of Hooke Jeeves is proved.
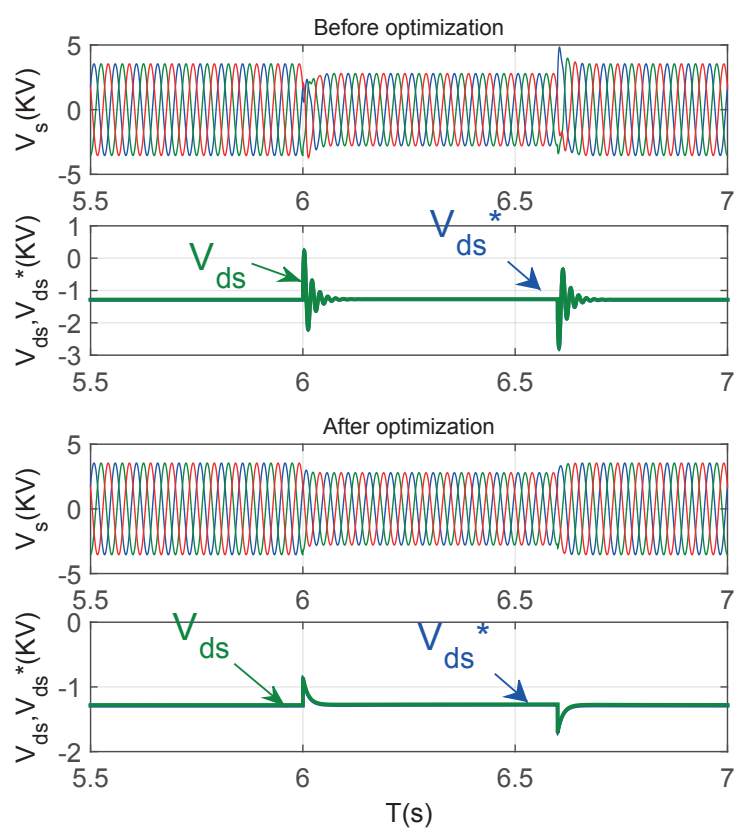

Fig. 9 AC voltage and active voltage during the step applied in $I_{d s}^{*}$

\subsection{Step changes in offshore voltage reference at turbine inverter side}

In the other side of the back to back link, a step change is applied in the offshore voltage reference $V_{d W}^{*}$ of the outer control loop which is used to control the inverter. The step is done at the moment $t=3 \mathrm{~s}$ for duration of 500 $\mathrm{ms}$ and after executing the simulation the new parameters are cited in Table 3.

The obtained results are demonstrated in Fig. 11 and Fig. 12. It is clearly seen from Fig. 11 that the active voltage reference $V_{d W}^{*}$ increasing caused an augmentation of the real active voltage $V_{d W}$ for the period of the step and also increasing in the offshore AC voltage $V_{W}$. It is also observed that the overshoots are eliminated and the response time to recover the functioning again is reduced from $0.2 \mathrm{~s}$ to $0.002 \mathrm{~s}$ with the new gains computed by the proposed approach. Also the behavior of the AC voltage is perfect after optimizing the PI gains.

In Fig. 12, the offshore frequency $F_{w}$ and the active $I_{d w}$ and reactive $I_{q w}$ currents and their references are presented. For the period of step change, the active and

Table 3 PI regulator gains

\begin{tabular}{lccc}
\hline PI Parameters & $K p$ & $K i$ & $\begin{array}{c}\text { Objective } \\
\text { function }\end{array}$ \\
\hline Before optimization & 50 & $1 \mathrm{e}-6$ & 9897.62 \\
After optimization & 100.483 & 0.129619 & 2427.55 \\
\hline
\end{tabular}




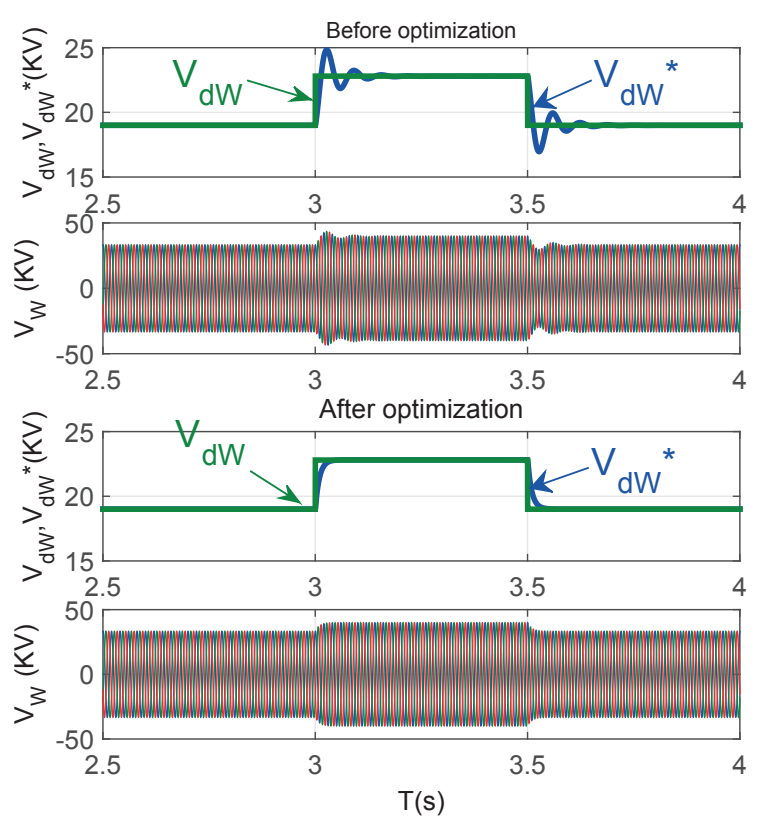

Fig. 11 Active voltage and AC voltage during the step applied in $V_{d W}^{*}$

reactive currents follow very well their references in which the active current and its reference are increased whereas the reactive current with its reference keep the rated value around zero. For the frequency, there are large transients at the beginning and the end of the step because of converter effect. Concerning the effect of the Hooke Jeevez method use, it is clear that this approach has a prefect influence to eradicate the oscillations and limit the response time.

\section{Conclusion}

In this work, the presented control strategies mainly use PI controllers optimized by the Hooke Jeeves method.

\section{References}

[1] Rodrigues, S. M. F., Pinto, R. T., Bauer, P., Pierik, J. "Optimal Power Flow Control of VSC-Based Multiterminal DC Network for Offshore Wind Integration in the North Sea", IEEE Journal of Emerging and Selected Topics in Power Electronics, 1(4), pp. 150-158, 2013. https://doi.org/10.1109/JESTPE.2013.2281917

[2] Chaudhary, S. K., Teodorescu, R., Rodriguez, P., Kjær, P. C. "Chopper controlled resistors in VSC-HVDC transmission for WPP with full-scale converters", In: IEEE PES/IAS Conference on Sustainable Alternative Energy, Valencia, Spain, 2009, pp. 1-8. https://doi.org/10.1109/SAE.2009.5534882

[3] Chunxue, W., Guojie, L., Peng, W., Zhengxi, L., Xiongwei, L., Fan, Z. "Vector control strategy for small-scale grid-connected PMSG wind turbine converter", In: $2^{\text {nd }}$ IEEE PES International Conference and Exhibition on Innovative Smart Grid Technologies, Manchester, UK, 2011, pp. 1-8. https://doi.org/10.1109/ISGTEurope.2011.6162678
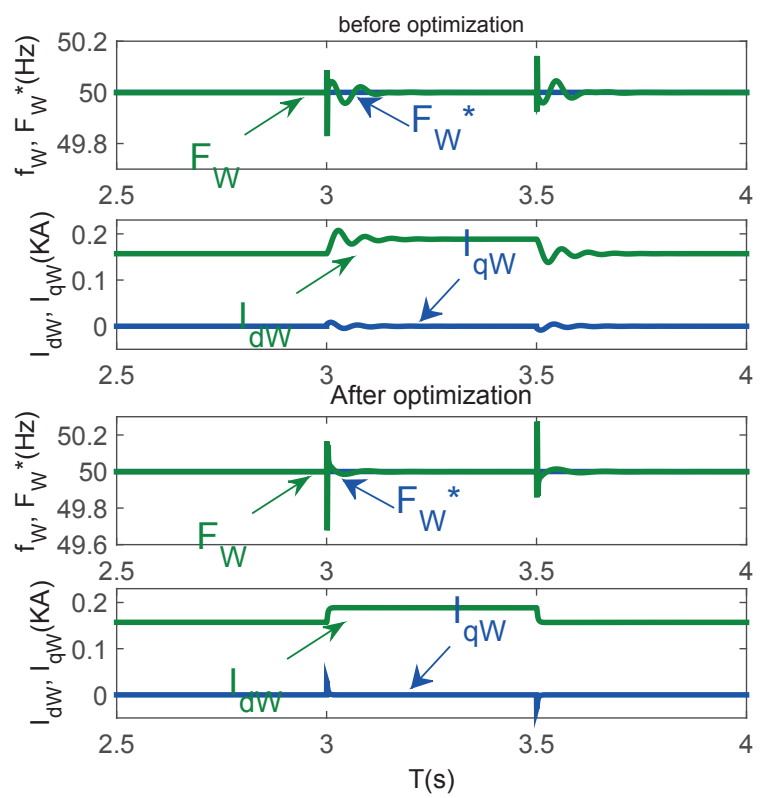

Fig. 12 Active and reactive voltages and frequency during the step change applied in $V_{d W}^{*}$

This approach has been introduced in the wind turbine control system for each used regulator. The simulation results prove the effectiveness of this approach to improve the operation of the control system and this leads to develop the efficiency of the wind turbine generator and consequently high offshore energy production is achieved. Also from these results, it can be concluded that this algorithm has the advantage of a perfect accuracy and a typical speed to find new PI parameters starting at initial ones taken from conventional method. As advanced work the synergy of this method with author method as Simplex method can be studied.

[4] Mazouz, L., Zidi, S. A., Saadi, S., Benmassaoud, T., Elaguab, M. "Hybrid Swarm Intelligence Approach Based PI Regulator for VSC-HVDC Optimal Parameters", Journal of Electrical Engineering, 14(2), pp. 256-262, 2014.

[5] Mazouz, L., Zidi, S. A., Saadi, S., Khatir, M., Benmassaoud, T. "VSC-HVDC system optimized PI controllers using bacterial foraging algorithm", Electrical Engineering, 97(3), pp. 205-212, 2015. https://doi.org/10.1007/s00202-014-0328-8

[6] Mazouz, L., Zidi, S. A., Khatir, M., Saadi, S., Benmassaoud, T. "Particle Swarm Optimization based PI controller of VSC-HVDC system connected to a wind farm", International Journal of System Assurance Engineering and Management, 7(1), pp. 239-246, 2016. https://doi.org/10.1007/s13198-015-0375-1 
[7] Jia, Z., Zhao, C. "Parameters Optimization of HVDC Control System Based on Simplex Algorithm in RTDS", In: IEEE $5^{\text {th }}$ International Conference on Critical Infrastructure, Beijing, China, 2010, pp. 1-6. https://doi.org/10.1109/CRIS.2010.5617529

[8] Toual, B. "Optimized Fuzzy Modeling and Control of a Double Power Generator, Application to a System Variable Speed Wind Turbines", MSc Thesis, University of Batna, 2010. [online] Available at: http://theses.univ-batna.dz/index.php/theses-enligne/doc_download/2373 [Accessed: 23 December 2010]

[9] Louar, F., Ouari, A., Omeiri, A., Djellad, A., Bouras, L. "Modeling and control of a permanent magnet synchronous generator dedicated to standalone wind energy conversion system", Frontiers in Energy, 10(2), pp. 155-163, 2016. https://doi.org/10.1007/s11708-016-0410-1

[10] Eklas, H., Jakir, H., Nazmus, S., Ramazan, B. "Modeling and Simulation of Permanent Magnet Synchronous Generator Wind Turbine: A Step to Microgrid Technology", International Journal of Renewable Energy Research, 7(1), pp. 444-450, 2017.

[11] Shilpa, M., Chatterji, S., Shimi, S. L., Sandeep, S. "Modeling and Control of Standalone PMSG WECS for Grid Compatibility at Varying Wind Speeds", International Journal of Engineering Trends and Technology, 17(10), pp. 495-501, 2014. https://doi.org/10.14445/22315381/IJETT-V17P297

[12] Chia, N. W., Wen, C. L., Xuan, K. L. "Modeling of a PMSG Wind Turbine with Autonomous Control", Mathematical Problems in Engineering, 2014, Article ID: 856173, 2014.

https://doi.org/10.1155/2014/856173

[13] Omessaad, E., Ben Hamed, M., Lassaad, S. "PMSG Wind Energy Conversion System: Modeling and Control", International Journal of Modern Nonlinear Theory and Application, 3(3), pp. 88-97, 2014. https://doi.org/10.4236/ijmnta.2014.33011

[14] Prasad, K. S., Rao, C. S., Nageswara, D. R. "Application of Hooke Jeeves method optimize ultimate tensile strength of pulsed current micro plasma arc welded inconel 625 nickel", International Journal of Lean Thinking, 3(1), pp. 42-52, 2012.
[15] Kirgat, G. S., Surde, A. N. "Review of Hooke and Jeeves direct search solution method analysis applicable to mechanical design engineering", International Journal of Innovations in Engineering Research and Technology, 1(2), Article ID: 140040, 2014. https://doi.org/10.5281/zenodo.1472095

[16] Kondapalli, S. P., Chalamalasetti, S. R., Damera, N. R. "Application of Hooke \& Jeeves Algorithm in Optimizing Fusion Zone Grain Size and Hardness of Pulsed Current Micro Plasma Arc Welded AISI 304L Sheets", Journal of Minerals and Materials Characterization and Engineering, 11(9), pp. 869-875, 2012. https://doi.org/10.4236/jmmce.2012.119081

[17] Ouabiba, M., Mebarki, N., Castagna, P. "Couplage entre des Methodes d'Optimisation Iteratives et des Modeles de Simulation a Evenements Discrets" (Coupling between iterative optimization methods and discrete event simulation models), In: $3^{\text {rd }}$ Francophone Conference of Modeling and Simulation, Troyes, France, 2001, pp. 56-63. (in French)

[18] Kealy, T., O'Dwyer, A. "Analytical ISE Calculation and Optimum Control System Design", In: Irish Signals and Systems Conference, Limerick, Ireland, 2003, pp. 265-273. [online] Available at: https://arrow.dit.ie/cgi/viewcontent.cgi?article=1145\& contex$\mathrm{t}=$ engscheleart [Accessed: 02 March 2003]

[19] Chalane, I., Ouari, T. "Optimization of the parameters of a PID by particulate swarms (PSO)", MSc Thesis, University of Bejaia, 2017. [online] Available at: http://www.univ-bejaia.dz/dspace/handle/123456789/3594 [Accessed: 07 July 2017]

[20] Blasco, G. R., Ano, V. S., Rodriguez, D. J., Bernal, P. S., Morant, F. "Diode-based HVdc Link for the Connection of Large Offshore Wind Farms", IEEE Transactions on Energy Conversion, 26(2), pp. 615-626, 2011. https://doi.org/10.1109/TEC.2011.2114886 